Tersedia online di: http://ejournal-balitbang.kkp.go.id/index.php/JP
e-mail:jurnalpari@gmail.com
JURNAL PARI
Volume 4 Nomor 2 Desember 2018
p-ISSN: 2502-0730
e-ISSN : 2549-0133

\title{
KEGIATAN PENYIANGAN KOLEKSI DI PERPUSTAKAAN STP JAKARTA
}

\author{
WIDYA INDARTI \\ Sekolah Tinggi Perikanan Jakarta, Badan Riset Dan Sumber Daya Manusia Kelautan Dan Perikanan \\ Diterima tanggal : 15 September 2018 Diterima setelah perbaikan : 18 Oktober 2018 \\ disetujui terbit : 18 Desember 2018
}

\begin{abstract}
ABSTRAK
Tidak semua pemustaka paham benar dalam mencari bahan pustaka di rak apalagi ketika koleksinya sudah banyak. Oleh karena itu pustakawan senantiasa harus cepat melakukan penempatan kembali bahan pustaka yang telah digunakan ke rak. Penentuan koleksi yang berpindah dari rak dilakukan secara berkala melalui kegiatan penyiangan koleksi secara rutin agar penempatan relatif dapat dipertahankan. Metode yang dipakai dalam penelitian ini adalah menggunakan kajian pustaka yakni mengumpulkan berbagai informasi yang terkait dengan kegiatan penyiangan dimana kegiatan ini adalah kegiatan rutin perpustakaan yang menjadi salah satu prasyarat akreditasi perpustakaan. Data-data yang diperoleh dari buku dan peraturan terbaru yang dikeluarkan oleh Perpustakaan Nasional RI merupakan bentuk pembaruan dokumen kegiatan penyiangan yang dilakukan setiap tahun. Metode pengumpulan data adalah dengan pengamatan langsung dan analisis data menggunakan metode deskriptif. Selain itu, penelitian ini juga menggunakan metode praktek kegiatan penyiangan yang dilakukan pustakawan dan petugas sejak April-Juni 2018 di Perpustakaan STP Jakarta, dimana kegiatan pengerakan kembali dilakukan pada 442 buku dan dikeluarkan dari jajaran rak disebabkan tidak sesuai penempatannya.
\end{abstract}

\section{Kata Kunci: Penyiangan; Pengerakan kembali koleksi; STP Jakarta; BRSDM; KKP.}

\section{ABSTRACT}

Mostly users unaware or do not understand well on how to browse collections to the shelves, more often if the library collections has already huge enough. Librarian need to put them to the right shelves after users finished to use the library collections. Identification of the library collections which has moved must be done regularly by weeding, so that relative classification can be fixed. This study use reference method by collecting whole kinds information related to weeding activity, which, it is regular activity and available with library accreditation. Datas are acquisitioned and new accreditation rules updated by National Library derived as yearly updated document especially weeding activity. This research used observation to data acquisition and analyze by descriptive method. Besides, this essay also use practical method, which has done by librarian and staffs since April to June 2018 at STP Jakarta Library, finally reshelving has utilized to 442 books and thrown out from their shelves because misplaced.

Keywords: Weeding; reshelving; STP Jakarta; BRSDM; KKP. 


\section{PENDAHULUAN}

Berbagai sarana dan program dirancang dengan harapan agar pemustaka datang ke perpustakaan STP Jakarta. Salah satu kegiatan rutin diperpustakaan yang mendukung layanan, adalah penyiangan koleksi. Penulis berpendapat keberadaan koleksi harus dibina, dirawat dan diatur secara tepat sehingga memudahkan pemustaka dalam mencari koleksinya. Tidak semua pemustaka paham benar dalam mencari bahan pustaka di rak apalagi ketika koleksinya sudah banyak. Oleh karena itu pustakawan senatiasa harus cepat melakukan penempatan kembali bahan pustaka yang telah digunakan ke rak. Penentuan koleksi yang berpindah dari rak dilakukan secara berkala melalui kegiatan pengerakan kembali koleksi secara rutin agar penempatan relatif dapat dipertahankan.

Layanan perpustakaan berarti penyediaan bahan pustaka secara tepat dan akurat, sesuai dengan kebutuhan pemustaka jasa perpustakaan. Sejak tahun 2004, perpustakaan STP Jakarta mengalami perubahan sistem layanan dari sistem tertutup (Close Access) kepada sistem terbuka (Open Access). Sistem layanan terbuka merupakan transformasi yang belum direncanakan secara matang pada waktu itu dan perpustakaan belum memiliki pedoman baku tertulis dalam menentukan sistem apa yang terbaik untuk memberikan layanan pustaka yang dapat memuaskan pengguna. Keterbatasan SDM adalah faktor yang menjadi penyebab utama penerapan sistem layanan terbuka hingga saat ini.

Sejalan dengan pertambahan koleksi perpustakaan yang memiliki kekhususan bidang kelautan dan perikanan di lingkungan perguruan tinggi, maka perlu dijelaskan kegiatan penyiangan yang mendukung layanan sistem terbuka ini. Sebagai bentuk tanggung jawab pustakawan, bahwa unsur penyiangan merupakan bagian dari layanan untuk membantu pemustaka menemukan koleksi yang dicari. Maka melalui tulisan ini, pustakawan mencoba menjelaskan beberapa hal yang telah dilakukan di perpustakaan dalam mempersiapkan layanan, seperti pengertian kegiatan penyiangan koleksi pustaka, metode penyiangan, alat dan bahan serta evaluasi yang dapat dilakukan.

\section{METODOLOGI}

Metode yang dipakai dalam tulisan ini adalah menggunakan kajian pustaka yakni mengumpulkan berbagai informasi yang terkait dengan kegiatan penyiangan dimana kegiatan ini adalah kegiatan rutin perpustakaan yang menjadi salah satu prasyarat akreditasi perpustakaan. Data-data yang diperoleh dari buku dan peraturan terbaru yang dikeluarkan oleh Perpustakaan Nasional RI sebagai bentuk pembaruan dokumen kegiatan penyiangan yang dilakukan setiap tahun di Perpustakaan STP Jakarta, khususnya tahun 2018. Metode pengumpulan data adalah dengan pengamatan langsung dan analisis data menggunakan metode deskriptif. Selain itu, kegiatan ini juga menggunakan metode praktek kegiatan penyiangan yang dilakukan penulis sejak April-Juni 2018 di Perpustakaan STP Jakarta.

\section{HASIL DAN PEMBAHASAN \\ 3.1Pengertian Kegiatan Penyiangan Koleksi Pustaka}

Di perpustakaan, Pustakawan perlu merawat koleksi yang dapat memenuhi kebutuhan pemustaka, salah satunya melalui penyiangan koleksi. Kegiatan penyiangan koleksi, berarti mengeluarkan koleksi yang sudah tidak sesuai, Pustaka yang dapat dikeluarkan dari rak koleksi disebabkan karena:

1. Isinya sudah tidak sesuai lagi

2. Perpustakaan sudah memiliki edisi yang terbaru

3. Rusak dan tidak dapat diperbaiki lagi

4. Isinya tidak lengkap lagi

5. Jumlahnya terlalu banyak dan jarang digunakan

6. Terlarang

Kegiatan ini merupakan salah satu cara pengaturan koleksi pustaka yang disarankan oleh Akreditasi Perpustakaan Perguruan Tinggi setiap setahun sekali sebagai kegiatan yang memiliki urgenitas dalam mendukung layanan.

Thompson (2008:4), berpendapat bahwa, penyiangan merupakan suatu praktek yang dilakukan untuk menarik koleksi atau mengirim koleksi yang kelebihan copy serta jarang digunakan dimana tingkat pemakaiannya sangat rendah.

Pada kegiatan ini penulis berpendapat bahwa penyiangan membantu untuk mengembangkan koleksi perpustakaan dengan menjaga bahan tetap up-to-date, relevan, akurat dan bermanfaat.

\subsection{Prosedur dan Tahapan Penyiangan Koleksi}

Penyiangan koleksi dilakukan melalui prosedur berikut:

1. Memilih pustaka yang akan dikeluarkan dari rak koleksi

2. Mengeluarkan kartu katalog pustaka yang dikeluarkan dari koleksi bila bahan tersebut merupakan satu-satunya yang dimiliki perpustakaan 
3. Memberi tanda atau cap pada pustaka yang yang dikeluarkan dari koleksi, agar diketahui bahwa pustaka tersebut bukan lagi milik perpustakaan

4. Mengirimkan pustaka yang masih dapat dimanfaatkan orang lain sebagai hadiah atau bahan tukar menukar

5. Memusnahkan pustaka yang sudah tidak dapat digunakan lagi

Sedangkan tahapan kegiatan penyiangan koleksi adalah sebagai berikut:

1. Menentukan tim penyiangan

2. Menentukan kriteria koleksi yang disiangi

3. Menentukan jenis koleksi yang disiangi

4. Mengeluarkan koleksi dari jajaran rak

5. Pencatatan hasil koleksi yang disiangi

6. Menghapus data dalam file di database

7. Penentuan status koleksi disimpan

8. Penempatan kembali dalam rak yang seharusnya

\subsection{Alat dan Bahan Penyiangan koleksi pustaka}

Alat dan Bahan Penyiangan koleksi pustaka terdiri dari:

1. Koleksi yang akan disiangi

2. Prosedur penyiangan

3. Tanda atau Cap pustaka

4. Komputer dan printer

5. ATK

6. Flash disk

\subsection{Praktik Kegiatan Penyiangan Koleksi Pustaka}

Praktik kegiatan penyiangan, dilakukan kapan saja, secara teratur setiap tahun dan ditentukan

Tabel 1. Judul-Judul Yang Disiangi Tahun 2018 kriterianya. Kegiatan tim penyiangan, ditujukan pada pustakawan sebagai koordinator layanan, kemudian ditujukan pada petugas perpustakaan yang melakukan kegiatan sirkulasi, apalagi yang disiangi akan ditujukan pada buku teks yang tersedia di daftar database perpustakaan, maka pustakawan membutuhkan berbagai keterampilan. Dalam hal ini, personil-personil dalam tim memiliki kemampuan mengerjakan kegiatan yang menjadi ruang lingkup penyiangan seperti, memeriksa kecocokan nomor panggil dengan database komputer, memeriksa kelengkapan buku, memeriksa kelengkapan halaman, memeriksa kelayakan isi dan kekhususannya, sudah adakah edisi yang terbaru, apakah jilidnya lepas dan masih bisa diperbaiki, menentukan dobel edisi yang sama sehingga dapat dihibahkan, intensitas penggunaan suatu judul sehingga dapat ditinjau kecukupan jumlah koleksi, ketersediaannya dalam database yang kita kenali dengan stock opname. Keterampilan-keterampilan tersebut akan sangat berguna untuk menyempurnakan rangkaian kegiatan penyiangan untuk mendapatkan kualitas koleksi yang terus diperbaharui dan bantuan layanan cepat jajaran koleksi bidang kelautan dan perikanan dapat selalu tersedia terutama pada saat database digunakan dalam penelusuran pengguna memiliki tingkat kecocokan pada jajaran buku di rak (shelf-match call number).

Pada kegiatan ini, pustakawan telah membuat tabel, yaitu : (1) tabel daftar judul pada tahun 2018 ini yang akan disiangi, (2) membuat tabel perlakukan dan (3) tabel daftar ketersediaan di database (stock opname) dan (4) tabel evaluasi pengerakan kembali. Berikut adalah tabel-tabel yang digunakan:

\begin{tabular}{llll}
\hline No & Kode Barcode & \multicolumn{1}{c}{ Nomor Panggil } & \multicolumn{1}{c}{ Judul } \\
\hline 1 & 0000000050 & $06.012: 915.2 / \mathrm{JAP} / \mathrm{j}$ & The Japan Foundation \\
2 & 0000000076 & $159.9 / \mathrm{POW} / \mathrm{t}$ & Tampilkan Jati Dirimu \\
3 & 0000000080 & $159.9 / \mathrm{SME} / \mathrm{m} / \mathrm{cop} 1$ & $\begin{array}{l}\text { Memanfaatkan Kekuatan } \\
\text { Yang Membebaskan }\end{array}$ \\
4 & 0000000098 & $181.07 / \mathrm{MUJ} / \mathrm{n}$ & $\begin{array}{l}\text { Nuansa -Nuansa } \\
\text { Psikologi Islam }\end{array}$ \\
\hline & dst. & & \\
\hline
\end{tabular}


Tabel 2. Tabel Perlakuan Weeding Atau Penyiangan

\begin{tabular}{|c|c|c|c|c|c|c|c|c|c|c|c|c|}
\hline \multirow{2}{*}{$\begin{array}{c}\text { Kode } \\
\text { Barcode }\end{array}$} & \multirow{2}{*}{$\begin{array}{l}\text { Nomor } \\
\text { Panggil }\end{array}$} & \multirow[b]{2}{*}{ Judul } & \multicolumn{2}{|c|}{$\begin{array}{l}\text { Kesesuaian } \\
\text { Isi }\end{array}$} & \multicolumn{2}{|c|}{$\begin{array}{l}\text { Edisi } \\
\text { Terbaru }\end{array}$} & \multicolumn{2}{|c|}{$\begin{array}{c}\text { Rusak } \\
\text { /Diperba } \\
\text { iiki }\end{array}$} & \multicolumn{2}{|c|}{$\begin{array}{c}\text { Keleng } \\
\text { kapan } \\
\text { Isi }\end{array}$} & \multicolumn{2}{|c|}{$\begin{array}{c}\text { Intensitas } \\
\text { Penggun } \\
\text { aan }\end{array}$} \\
\hline & & & $\begin{array}{l}\text { Ma } \\
\text { sih }\end{array}$ & $\begin{array}{c}\text { Tidak } \\
\text { Sesu } \\
\text { ai }\end{array}$ & $\begin{array}{c}\text { Ad } \\
\mathbf{a}\end{array}$ & $\begin{array}{c}\text { Tidak } \\
\text { ada }\end{array}$ & $\begin{array}{l}\text { Da } \\
\text { pat }\end{array}$ & $\begin{array}{c}\mathrm{Ti} \\
\mathrm{da} \\
\mathbf{k}\end{array}$ & $\begin{array}{c}\text { Le } \\
\text { ng } \\
\text { ka } \\
\text { p }\end{array}$ & $\begin{array}{c}\mathrm{Ti} \\
\mathrm{da} \\
\mathbf{k}\end{array}$ & $\begin{array}{l}\text { Ser } \\
\text { ing }\end{array}$ & $\begin{array}{c}\text { Jara } \\
\text { ng }\end{array}$ \\
\hline 0000000050 & $\begin{array}{l}06.012: 9 \\
\text { 15.2/JAP } \\
\text { /j }\end{array}$ & $\begin{array}{l}\text { The } \\
\text { Japan } \\
\text { Foundat } \\
\text { ion }\end{array}$ & $\sqrt{ }$ & & & $\sqrt{ }$ & $\sqrt{ }$ & & $\sqrt{ }$ & & & $\sqrt{ }$ \\
\hline 0000000076 & $\begin{array}{l}159.9 / \mathrm{PO} \\
\mathrm{W} / \mathrm{t}\end{array}$ & $\begin{array}{l}\text { Tampilk } \\
\text { an Jati } \\
\text { Dirimu }\end{array}$ & $\sqrt{ }$ & & & $\sqrt{ }$ & $\sqrt{ }$ & & $\sqrt{ }$ & & & $\sqrt{ }$ \\
\hline 0000000080 & $\begin{array}{l}\text { 159.9/SM } \\
\mathrm{E} / \mathrm{m} / \mathrm{cop} \\
1\end{array}$ & $\begin{array}{l}\text { Memanf } \\
\text { aatkan } \\
\text { Kekuata } \\
\text { n Yang } \\
\text { Membe } \\
\text { baskan }\end{array}$ & $\sqrt{ }$ & & & $\sqrt{ }$ & $\sqrt{ }$ & & $\sqrt{ }$ & & & $\sqrt{ }$ \\
\hline 0000000098 & $\begin{array}{l}181.07 / \mathrm{M} \\
\mathrm{UJ} / \mathrm{n}\end{array}$ & $\begin{array}{l}\text { Nuansa } \\
\text {-Nuansa } \\
\text { Psikolog } \\
\text { i Islam }\end{array}$ & $\sqrt{ }$ & & & $\sqrt{ }$ & $\sqrt{ }$ & & $\sqrt{ }$ & & $\sqrt{ }$ & \\
\hline
\end{tabular}

dst.

Tabel 3. Tabel Ketersediaan Pada Database

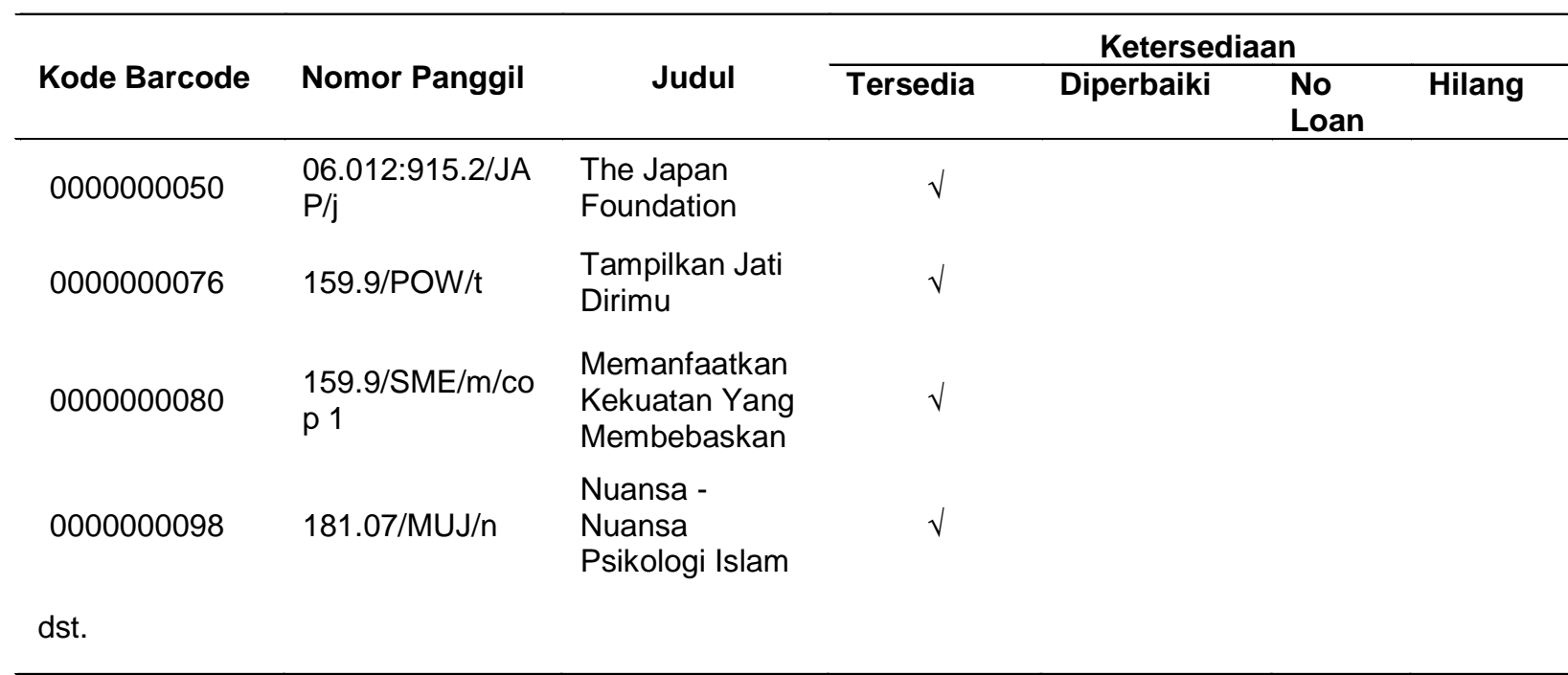


Tabel 4. Tabel Evaluasi Judul-Judul Yang Disimpan/ Di Rak Kan Kembali

\begin{tabular}{|c|c|c|c|}
\hline No & Kode Barcode & Nomor Panggil & Judul \\
\hline \multicolumn{4}{|c|}{ Kelas 00 - 09 Generalities ... } \\
\hline 1 & 0000000050 & 06.012:915.2/JAP/j & The Japan Foundation \\
\hline \multicolumn{4}{|c|}{ Kelas 10 Philosophy, Psychology } \\
\hline 1 & 0000000076 & 159.9/POW/t & Tampilkan Jati Dirimu \\
\hline 2 & 0000000080 & 159.9/SME/m/cop 1 & $\begin{array}{l}\text { Memanfaatkan Kekuatan Yang } \\
\text { Membebaskan }\end{array}$ \\
\hline 3 & 0000000098 & 181.07/MUJ/n & Nuansa -Nuansa Psikologi Islam \\
\hline \multicolumn{4}{|c|}{ Kelas 20 Religion, Theology } \\
\hline 5 & 0000000179 & 297.1/MUH/m & $\begin{array}{l}\text { Metode Menjemput Maut Seperti } \\
\text { Rasulullah }\end{array}$ \\
\hline dst. & & & \\
\hline
\end{tabular}
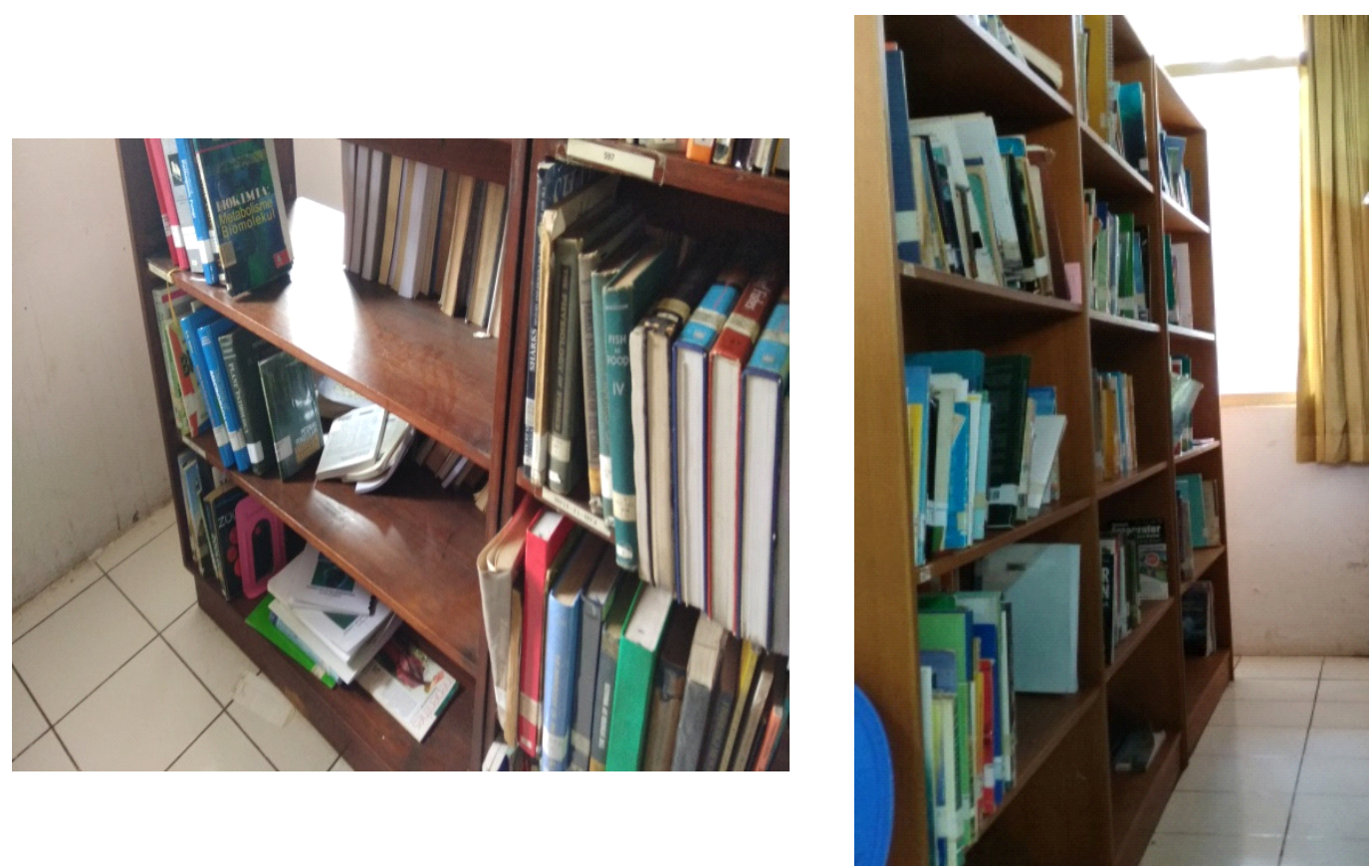

Gambar 1. Koleksi yang akan disiangi 
Proses kegiatan ini, dapat digambarkan melalui alur sebagai berikut:

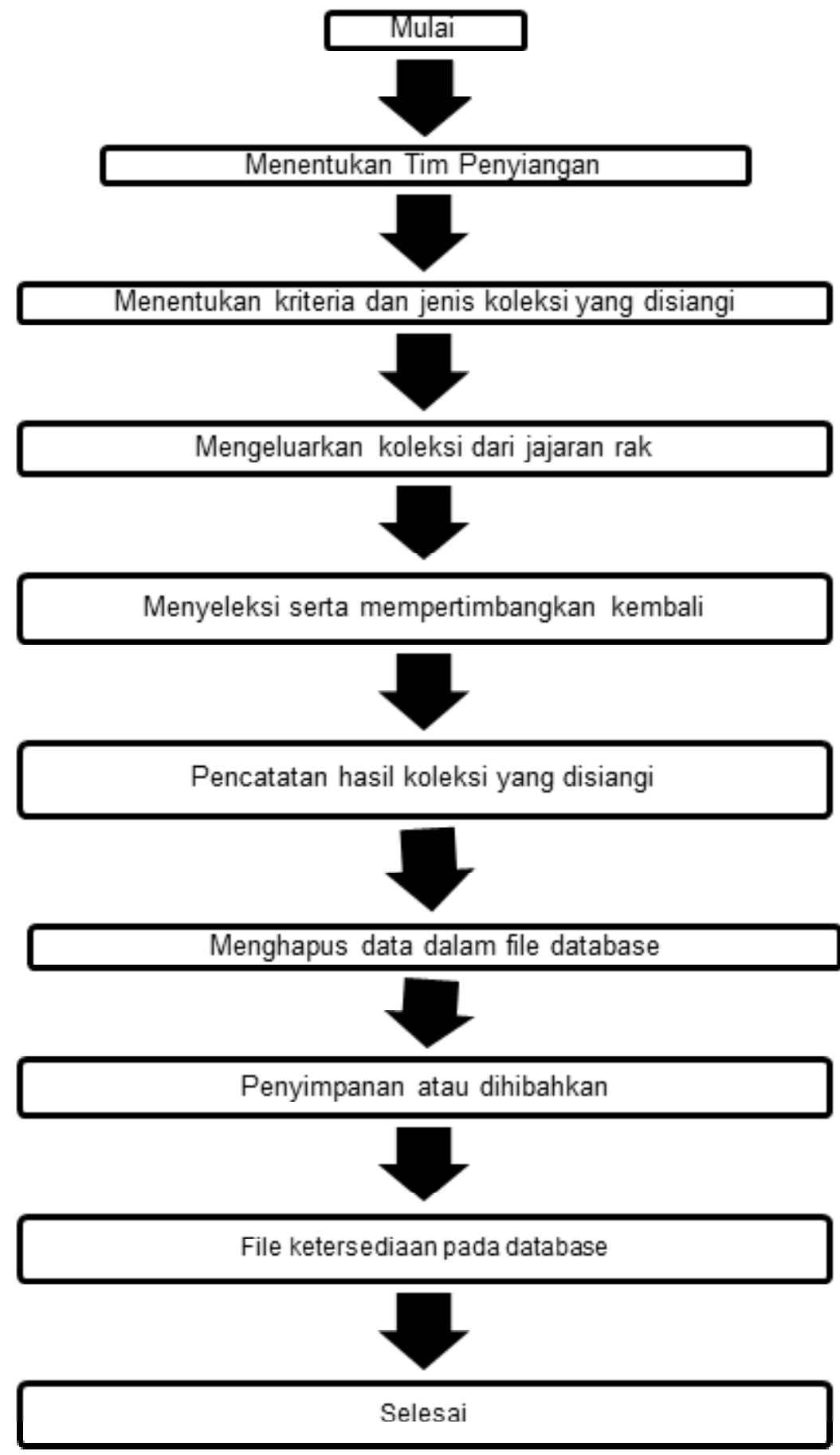

Gambar 2. Alur Kegiatan Penyiangan

\subsubsection{Menentukan tim penyiangan}

Proses kegiatan penyiangan setiap harinya dapat dilakukan oleh 2-3 orang, disela-sela layanan.
Tim yang ikut serta dalam kegiatan penyiangan, terlebih dahulu didata, pada tabel sebagai berikut: 


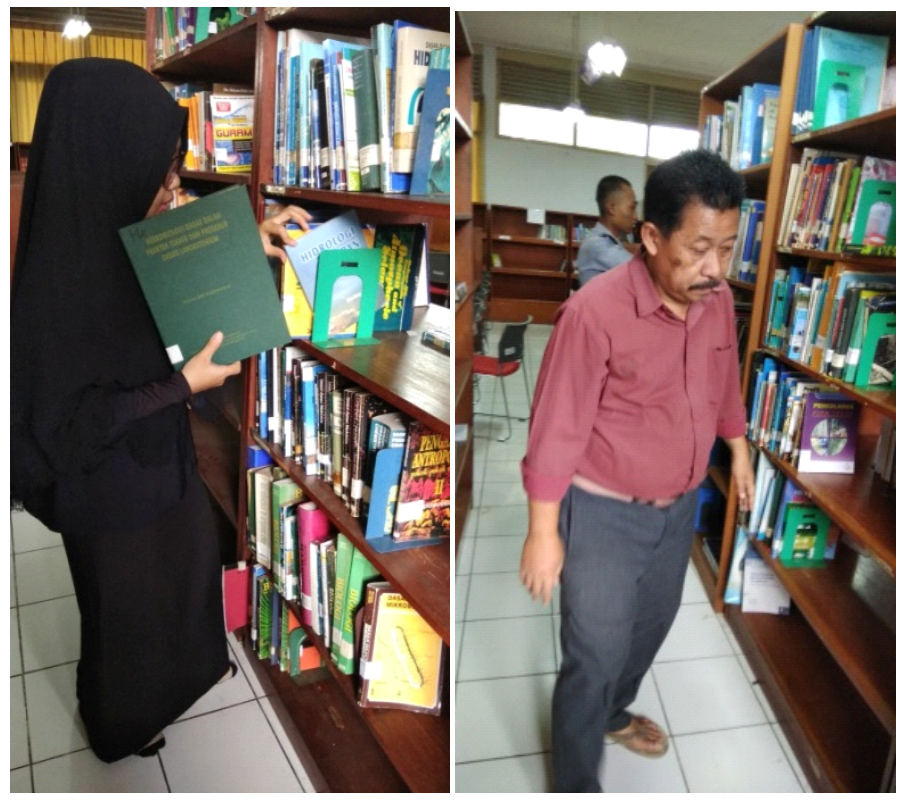

Gambar 4. Tim penyiangan Perpustakaan STP Jakarta tahun 2018

\begin{tabular}{clcc}
\hline No & \multicolumn{1}{c}{ Nama } & Jabatan & Keterangan \\
\hline 1. & Nunung Sabariyah & Kepala Unit & Penangung Jawab \\
2. & Widya Indarti & Pustakawan Pertama & Koordinator \\
3. & Agus Mansyur & Petugas & Anggota \\
4. & Murtani & Petugas & Anggota \\
5. & Adinda Dwi & Petugas & Anggota \\
6. & Agung Hariadi & Petugas Magang CPNS & Anggota \\
7. & lin Fridayani & Petugas Magang CPNS & Anggota \\
\hline
\end{tabular}

\subsubsection{Menentukan kriteria dan jenis koleksi yang disiangi}

Pada tahun 2018 ini pustakawan telah mengidentifikasi 442 judul buku teks yang berada pada jajaran rak relatif. Hasil identifikasi menunjukkan kesalahan pengerakan atau tidak sesuainya nomor panggil dengan kode rak. Oleh karena itu koleksi ini diturunkan dari rak, didaftar judulnya untuk kemudian dapat ditentukan perlakuan selanjutnya.

\subsubsection{Mengeluarkan koleksi dari jajaran rak}

Pada tahap ini pustakawan memilih serta mengeluarkan koleksi-koleksi yang termasuk syarat koleksi yang harus disiangi seperti koleksi yang intensitas penggunaannya jarang, serta kondisi fisik koleksi rusak. Kegiatan ini dilakukan setiap hari sembari merapikan koleksi yang ada di jajaran rak. Selain pemilihan pada buku teks juga mengadakan pemilihan pada koleksi majalah dan jurnal., dikarenakan kedua koleksi tersebut sering muncul terbitan baru sehingga koleksi majalah dan jurnal yang sudah lama akan ditarik dari jajaran koleksi dan sering masuk ke jajaran buku teks.

\subsubsection{Menyeleksi serta mempertimbangkan kembali}

Berdasarkan pengamatan yang dilakukan oleh peneliti, kondisi fisik koleksi buku yang dikeluarkan dari jajaran koleksi tersebut memiliki kondisi yang berbeda-beda antara koleksi satu dengan koleksi yang lainnya. Kondisi koleksi buku teks yang disiangi ada yang mengalami rusak ringan dan ada yang mengalami rusak berat, namun keseluruhannya dapat diperbaiki. Selanjutnya koleksi-koleksi yang memiliki dobel edisi, masih diperlukan untuk mencukupi kebutuhan pengguna. Isibuku masih sesuai dan halamannya masih lengkap, siap untuk disimpan kembali. 


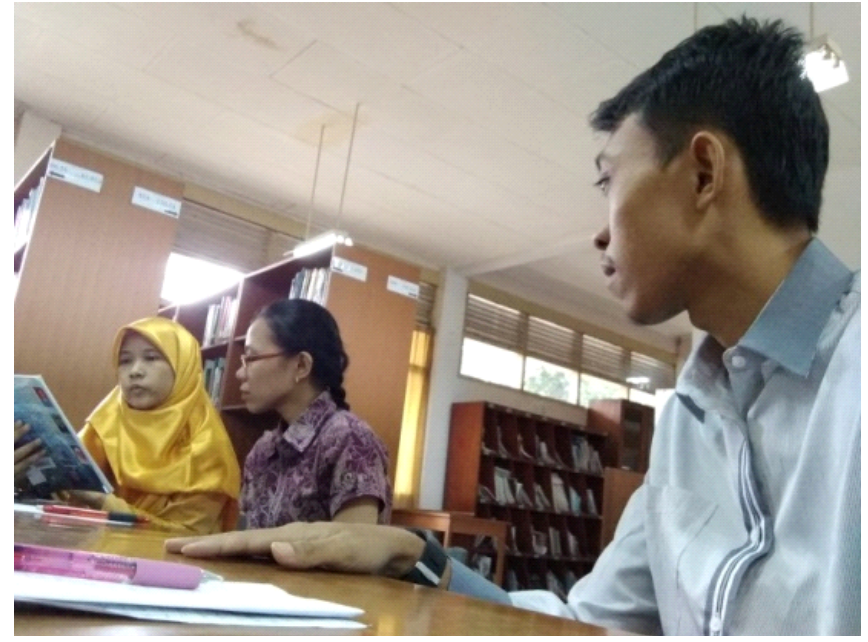

Gambar 2. Kegiatan Menyeleksi dan Mempertimbangkan koleksi
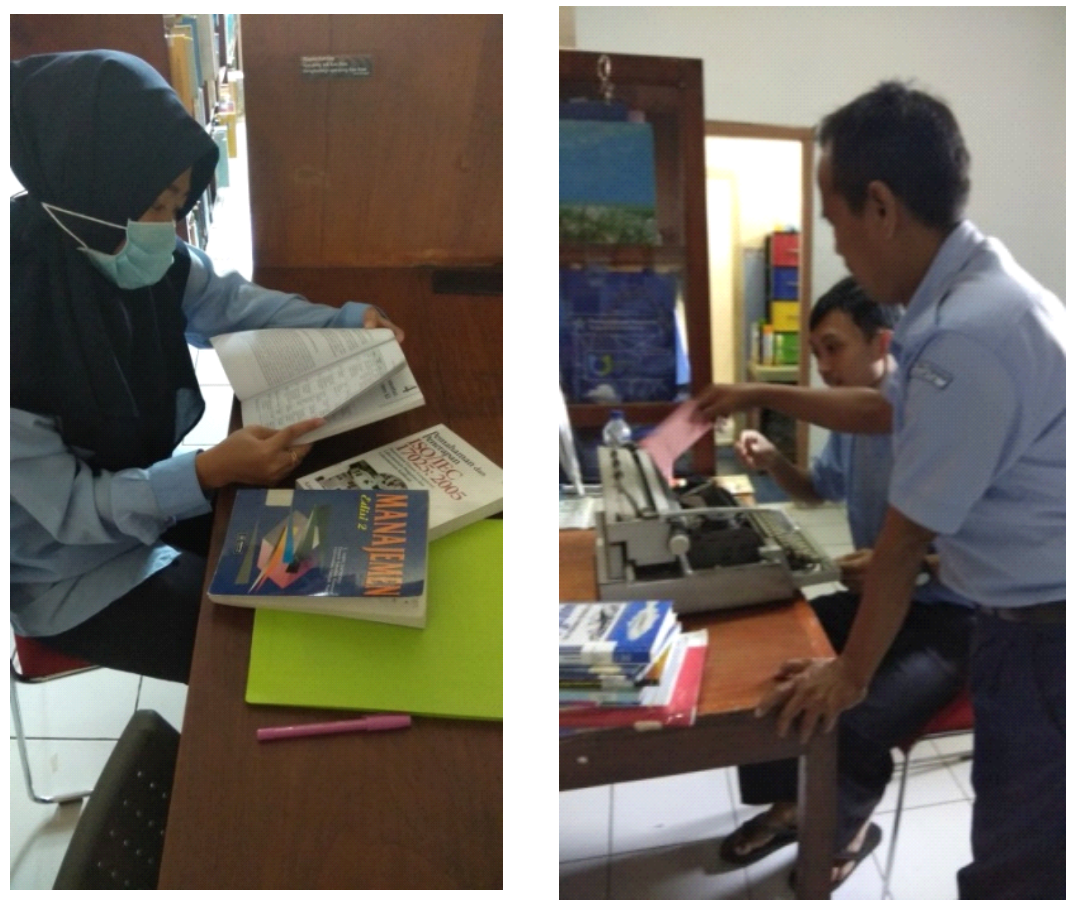

Gambar 3. Pengecekan halaman dan perbaikan koleksi

\subsubsection{Pencatatan hasil koleksi yang disiangi}

Pencatatan hasil koleksi yang disiangi menggunakan tabel 3 , yaitu tabel ketersediaan pada database. Disini, diperlukan penghitungan kembali, koleksi yang dimiliki dan ketersediaannya di perpustakaan. Kriteria atau status pada tabel tersebut diperlukan untuk selain ketersediaan adapula diperbaiki, tidak dipinjamkan dan hilang. Langkahlangkah tersebut disebut stock opname, yaitu suatu praktek memastikan keberadaan dan jumlah koleksi di perpustakaan. Perlakuan yang diterima pada 442 buah teks buku yang disiangi adalah status tersedia. Pada tahapan ini tahapan menghapus file dan menghibahkan dalam kegiatan penyiangan tidak dilakukan, namun reshelving adalah tugas pustakawan dan petugas untuk menyimpan kembali di rak yang benar. Hal ini disebabkan ketersediaan judul bidang studi, eksemplar yang dibutuhkannya berjumlah 5-10 eksemplar. 


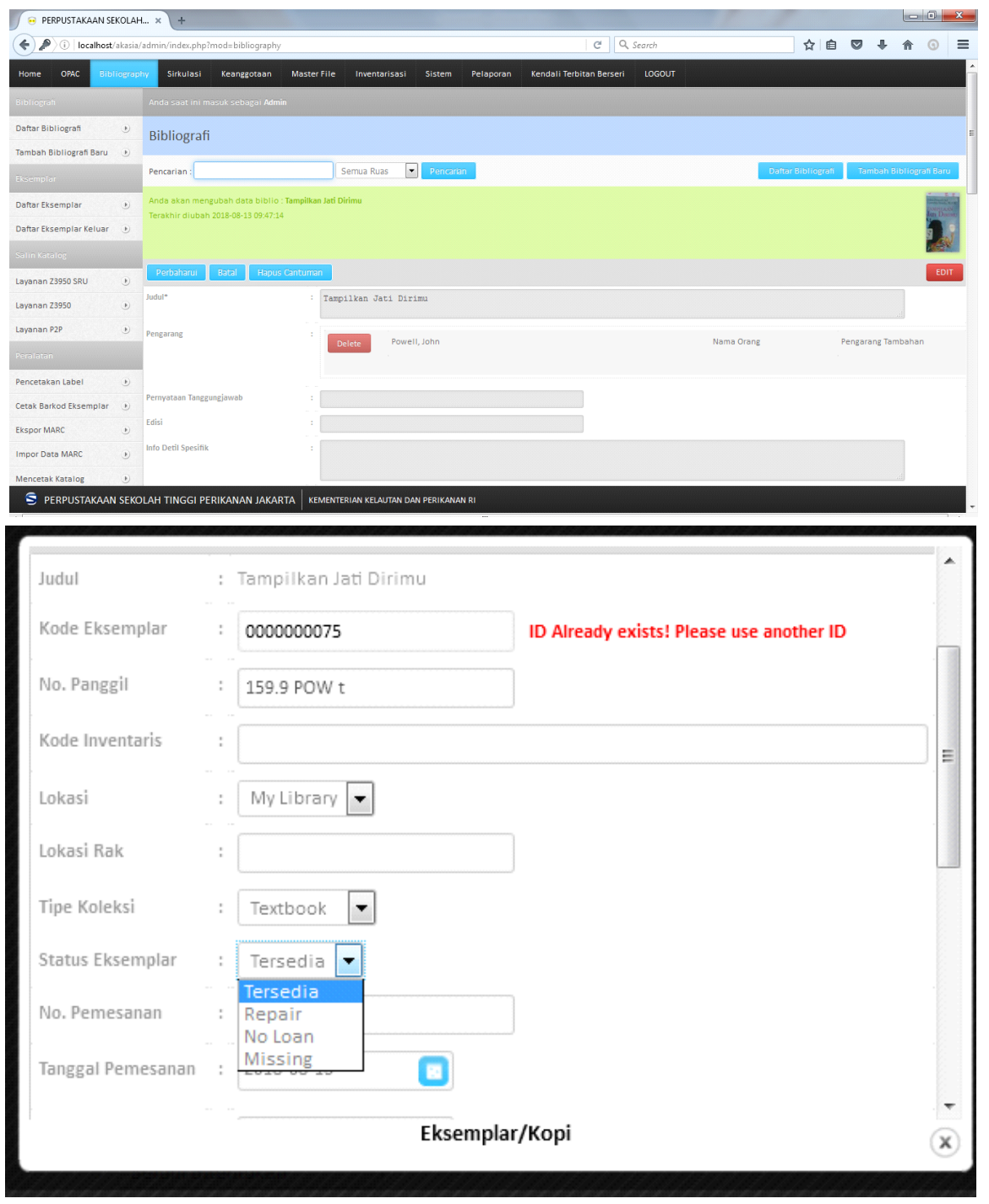

Gambar 4. Kegiatan Pencatatan hasil koleksi yang disiangi pada database

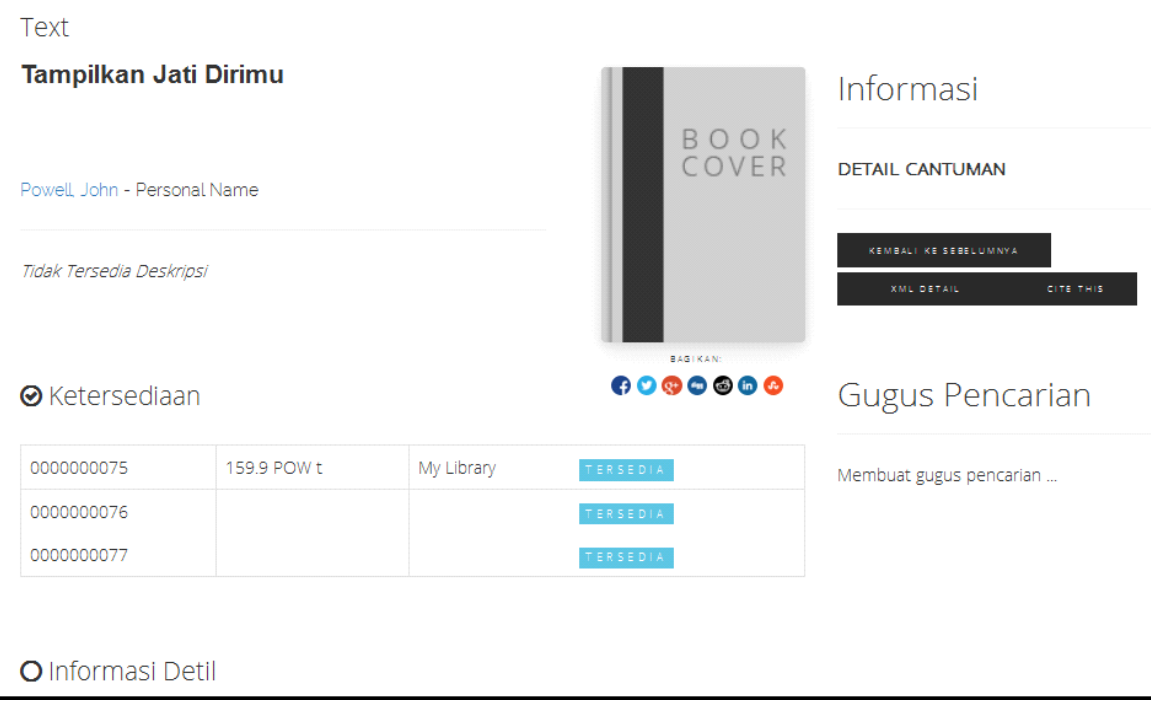

Gambar 5. Pencatatan "ketersediaan" pada koleksi, pada gambar tertulis TERSEDIA 

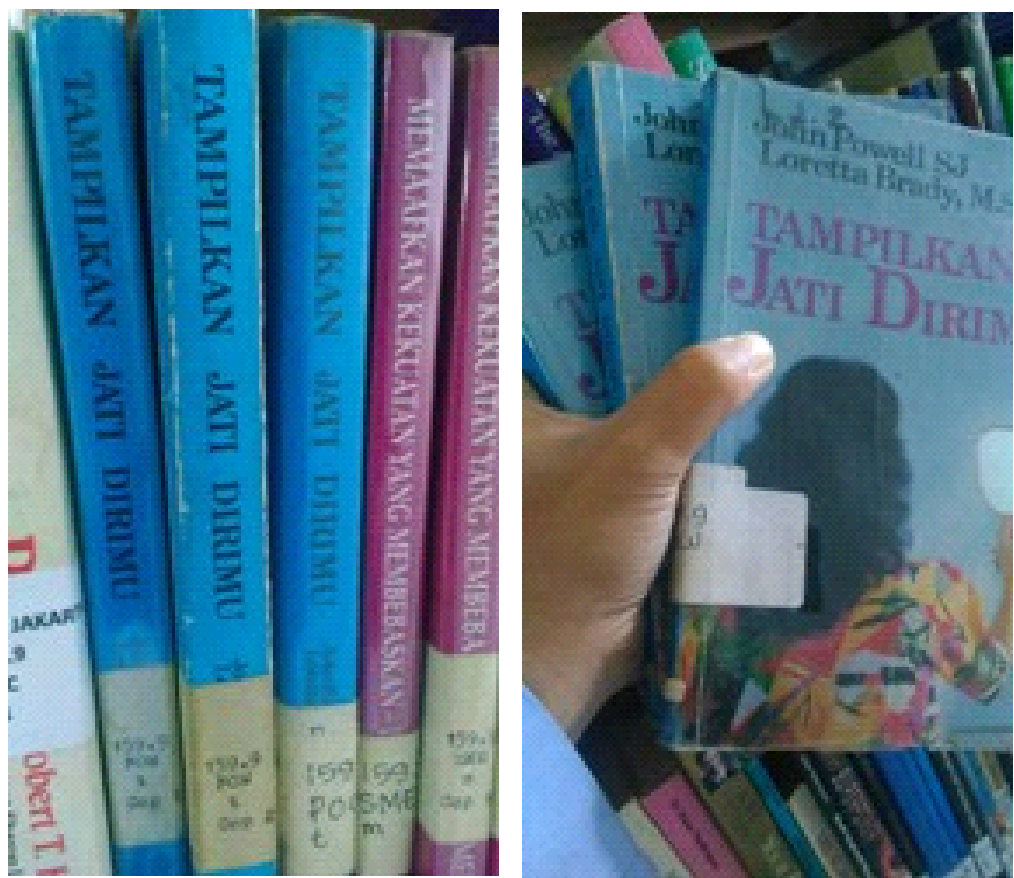

Gambar 6. Ketersediaan Judul Buku “Tampilkan Jati Dirimu” pada Hasil Browsing di Rak

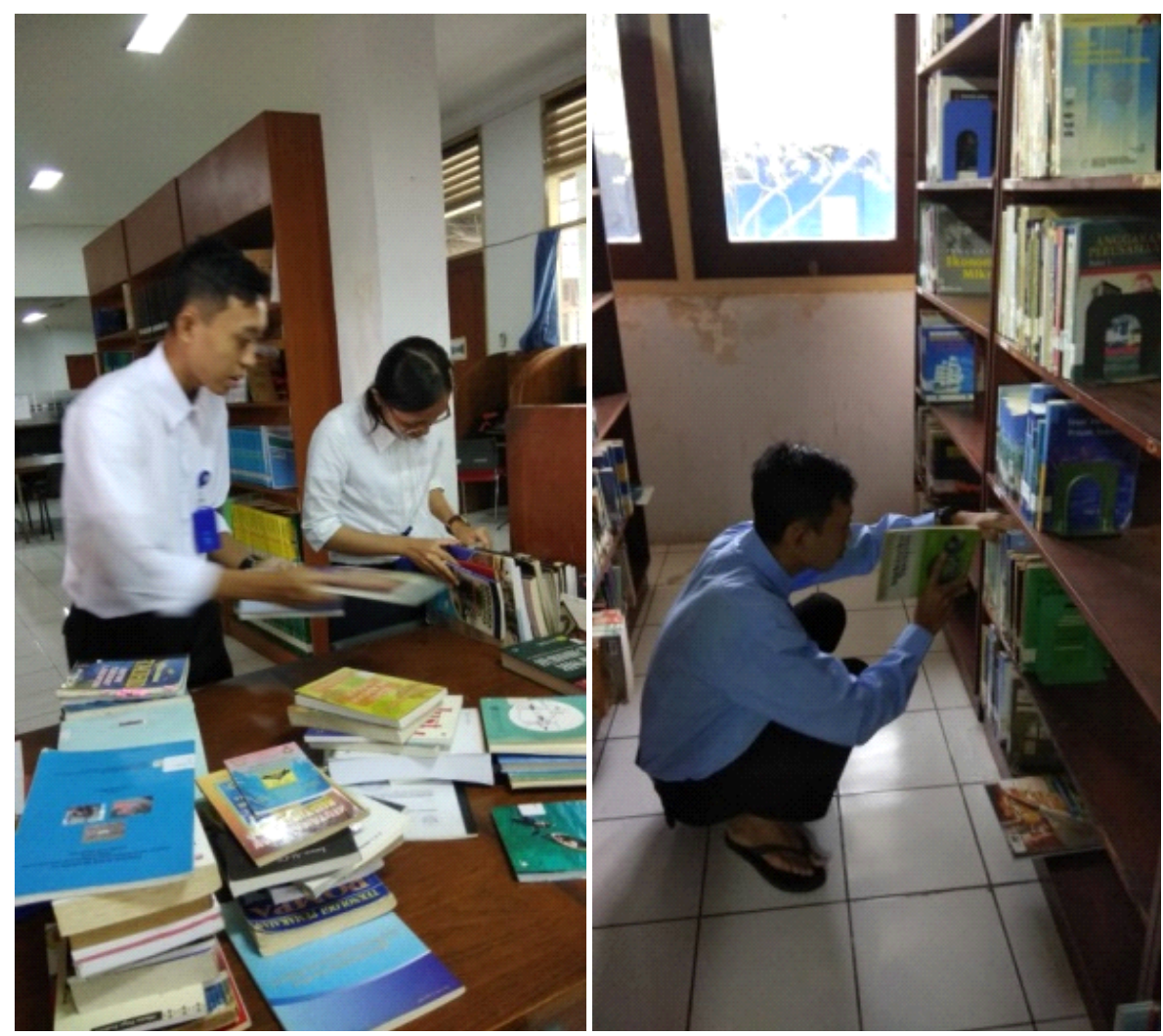

Gambar 7. Proses pengelompokkan berdasarkan klasifikasi dan pengerakan kembali pada jajaran rak yang sesuai 


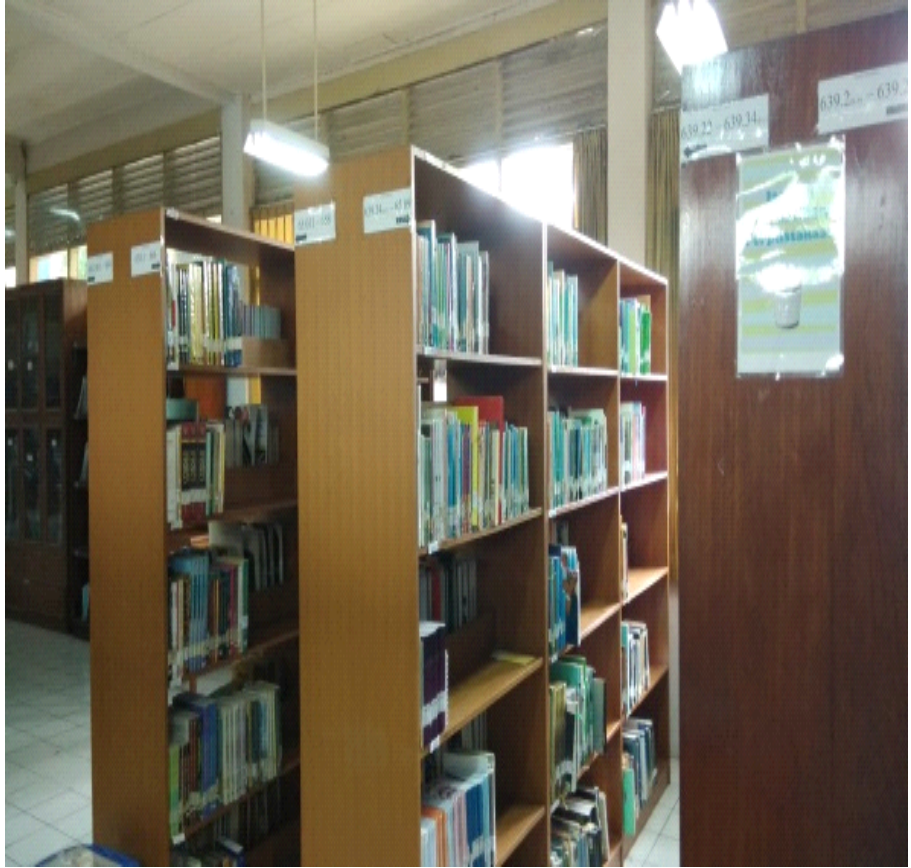

Gambar 7. Kondisi Buku teks yang telah di tempatkan kembali dalam rak yang seharusnya

\section{Simpulan}

Berdasarkan hasil penelitian yang telah dipaparkan, maka simpulan yang dapat diambil dari penelitian ini adalah

1. Penyiangan bahan pustaka telah dilakukan pada tahun ini, yaitu penyiangan buku teks sebanyak 442 buah teks buku dan telah diperbarui sistem yang baku/prosedur yang jelas pada pelaksanaan kegiatan penyiangan bahan pustaka pada tahun 2018.

2. Kriteria buku teks yang disiangi adalah:
a. Isinya masih sesuai atau sudah tidak sesuai
b. Ada atau tidak adanya edisi terbaru
c. Rusak, dapat diperbaiki atau tidak
d. Kelengkapan isi, lengkap atau tidak
e. Intensitas penggunaan, sering atau jarang

3. Alat dan Bahan Penyiangan koleksi pustaka terdiri dari:
a. Koleksi yang akan disiangi
b. Prosedur penyiangan
c. Tanda atau Cap pustaka
d. Komputer dan printer
e. ATK
f. Flash disk

4. Tahapan atau prosedur yang telah dilaksanakan adalah sebagai berikut:
a. Menentukan tim penyiangan
b. Menentukan kriteria koleksi yang disiangi
c. Menentukan jenis koleksi yang disiangi
d. Mengeluarkan koleksi dari jajaran rak
e. Pencatatan hasil koleksi yang disiangi

f. Menghapus data dalam file database

g. Penentuan status koleksi disimpan

h. Penempatan kembali dalam rak yang seharusnya

5. Kendala yang dihadapi dalam proses penyiangan ini, adalah:

a. Tidak adanya waktu khusus dalam penyiangan

b. Kurangnya SDM perpustakaan

c. Kehati-hatian dalam menentukan kriteria penyiangan

d. Belum adanya inisiatif melakukan hibah pada judul-judul yang lebih dari 5 eksemplar untuk dihibahkan karena sangat diperlukan dan belum adanya judul yang baru serta terkait kurikulum.

e. Rasa takut melakukan kesalahan terhadap koleksi yang disiangi

f. Keseluruhan koleksi yang disiangi tidak ada yang mengalami rusak berat

\section{Saran}

Saran dalam penelitian ini adalah:

1. Perlunya kebijakan penyiangan dengan SOP tertulis yang terbarukan setiap tahunnya dengan waktu khusus penyiangan, misalnya saat libur taruna/ taruni.

2. Perlunya ditentukan kriteria bagi tiap-tiap jenis koleksi terkait kurikulum dan bahan ajar dalam kegiatan penyiangan.

3. Tersedianya SDM penyiangan yang terampil, memahami kegiatan penyiangan yang dapat 
membantu tersedianya literatur khusus kelautan dan perikanan berkualitas yang sesuai dengan pengguna.

4. Tersedianya jumlah SDM penyiangan, untuk setiap jenis koleksi.

\section{DAFTAR PUSTAKA}

Fithria Rizka S, Hermintoyo, Putut Suharso. 2014. Analisis Penyiangan Bahan Pustaka Tercetak Terhadap Kualitas Koleksi Di Perpustakaan Daerah Provinsi Jawa Tengah.Semarang: Jurusan IImu Perpustakaan, Fakultas IImu Budaya, UNDIP

Mukhtar. 2013. Metode Penelitian Deskriftif Kualitatif. Jakarta : GP Press Group

Perpustakaan Nasional RI. 2013. Revisi Pedoman Pengelolaan Koleksi Perpustakaan Perguruan Tinggi. Jakarta: Perpusnas RI
Perpustakaan Nasional RI. 2014. Instrumen Akreditasi Perpustakaan Perguruan Tinggi. Jakarta: Perpusnas RI

Sugiyono. 2008. Metode Penelitian Pendidikan: Penelitian Kuantitatif \& Kualitatif, dan R\&D. Bandung: Alfabeta.

Suwarno, Wiji. 2010. Pengetahuan Dasar Kepustakaan. Bogor: Ghalia Indonesia.

Tim Penyusun Kamus Pusat bahasa.2005. Kamus Besar Bahasa Indonesia.Jakarta: Balai Pustaka.

Tohirin.2012. Metode Penelitian Kualitatif dalam Pendidikan dan Bimbingan Konseling. Jakarta: Rajawali Pers.

www.pnri.go.id, Peraturan Kepala Perpustakaan Nasional nomor 13 tahun 2017 diunduh pada bulan Mei 2018 